\title{
The left lung is preferentially targeted during experimental paracoccidioidomycosis in C57BL/6 mice
}

\author{
F.S.M. Tristão ${ }^{1}$, F.A. Rocha ${ }^{1}$, F.C. Dias ${ }^{1}$, M.A. Rossi ${ }^{2}$ and J.S. Silva ${ }^{1}$ \\ ${ }^{1}$ Departamento de Bioquímica e Imunologia, Faculdade de Medicina de Ribeirão Preto, \\ Universidade de São Paulo, Ribeirão Preto, SP, Brasil
}

${ }^{2}$ Departamento de Patologia, Faculdade de Medicina de Ribeirão Preto, Universidade de São Paulo, Ribeirão Preto, SP, Brasil

\begin{abstract}
Paracoccidioidomycosis (PCM) is a chronic systemic mycosis caused by the inhalation of the thermally dimorphic fungus Paracoccidioides brasiliensis as well as the recently described $P$. lutzii. Because the primary infection occurs in the lungs, we investigated the differential involvement of the right and left lungs in experimental $P$. brasiliensis infection. Lungs were collected from C57BL/6 mice at 70 days after intravenous infection with $1 \times 10^{6}$ yeast cells of a virulent strain of $P$. brasiliensis $(\mathrm{Pb} 18)$. The left lung, which in mice is smaller and has fewer lobes than the right lung, yielded increased fungal recovery associated with a predominant interleukin-4 response and diminished synthesis of interferon- $\gamma$ and nitric oxide compared with the right lung. Our data indicate differential involvement of the right and left lungs during experimental PCM. This knowledge emphasizes the need for an accurate, standardized protocol for tissue collection during studies of experimental $P$. brasiliensis infection, since experiments using the same lungs favor the collection of comparable data among different mice.
\end{abstract}

Key words: Lung; Paracoccidioidomycosis; Paracoccidioides brasiliensis

\section{Introduction}

Paracoccidioidomycosis (PCM) is a chronic systemic mycosis caused by the thermally dimorphic fungus Paracoccidioides brasiliensis as well as the recently described $P$. lutzii (1). The incidence and prevalence of PCM are significant in Latin American countries, such as Brazil, Colombia, Venezuela, Ecuador, and Argentina, where this disease is considered to be endemic in nonmetropolitan and rural areas (2).

PCM occurs more often in men, with a mean maleto-female patient ratio of $15: 1$. In many areas of Latin America, PCM has high mortality and lethality rates and is the eighth most common cause of death from predominantly chronic or recurrent infectious and parasitic diseases (3). Thus, PCM has become an important occupational disease and a serious public health problem because it presents several recurrences and usually leads to the development of anatomical sequelae.

Epidemiological studies have shown that the vast majority of people who live in endemic areas do not develop this disease (4). However, the clinical manifestations of
PCM can be observed in infected individuals as consequences of primary infection, reactivation of quiescent foci after a period of latency (endogenous reactivation), or exogenous reinfection after previous exposure to the pathogen (5). Once established, the PCM can either be eliminated or progress, leading to the formation of quiescent or latent foci in a manner dependent on both host and fungal factors (6). The primary infection occurs in the lungs, where it causes chronic granulomatous inflammation of the parenchyma. However, this disease can progress by fungal proliferation and dissemination through both hematogenous and lymphatic routes, with an outcome compromising several extrapulmonary tissues (7).

No information is available regarding differential involvement of the right and left lungs in mice after $P$. brasiliensis infection. The objective of this study was to evaluate fungal recovery and nitric oxide (NO) and interferon- $\gamma($ IFN- $\gamma)$ production in the lung tissues of C57BL/6 mice in a late phase of intravenous infection with $P$. brasiliensis yeast cells.

Correspondence: F.S.M. Tristão, Departamento de Bioquímica e Imunologia, Faculdade de Medicina de Ribeirão Preto, USP, Av. Bandeirantes, 3900, 14049-900 Ribeirão Preto, SP, Brasil. Fax: +55-16-3633-6840. E-mail: fabrinemassafera@yahoo.com.br 


\section{Material and Methods}

\section{Animals}

Male C57BL/6 mice, 6-8 weeks of age, were obtained from our Isogenic Breeding Unit and maintained under specific pathogen-free conditions in microisolator cages in the animal housing facility of the Departamento de Bioquímica e Imunologia, Faculdade de Medicina de Ribeirão Preto, Universidade de São Paulo, Brazil. The animals were supplied with sterilized food and water ad libitum. The Ethics Committee for Animal Experimentation of USP approved all of the experimental protocols described in the present study.

\section{Fungus and mice infection}

Yeast cells of $P$. brasiliensis 18 (Pb18), a highly virulent strain, were used throughout this study. This isolate was maintained as yeast-form cells in brain heart infusion (BHI) culture medium for 7 days at $37^{\circ} \mathrm{C}$, at which time the fungal cells were collected, washed in phosphate-buffered saline (PBS), pH 7.2, and counted on a hemocytometer. The viability of the fungal suspensions was determined by fluorescein diacetate-ethidium bromide staining (8). The mice were anesthetized and infected intravenously (iv) through the venous plexus in the orbital cavity with $1 \times 10^{6}$ $\mathrm{Pb} 18$ yeast cells. Control mice received sterile PBS.

\section{Colony-forming unit (CFU) experiments}

The numbers of viable fungal cells in the lungs were quantified by CFU counts as previously described (9). Six mice were killed at day 70 postinfection (pi). The organs were weighed and individually mechanically homogenized (Ika-Werke, GMB4 \& Co. KG, Germany) in $1 \mathrm{~mL}$ PBS. A $100-\mu \mathrm{L}$ sample of each homogenate was diluted 1:10 in PBS and plated on $\mathrm{BHI}$ agar supplemented with $5 \%(\mathrm{v} / \mathrm{v})$ inactivated fetal calf serum and $5 \% P$. brasiliensis strain 265 culture filtrate. The plates were incubated at $37^{\circ} \mathrm{C}$, the colonies were counted 14 days later, and the numbers of $\mathrm{CFU} / \mathrm{g}$ tissue were calculated.

Nitrite and cytokine quantification in lung tissue. The lungs were removed, weighed, individually homogenized, and centrifuged as described above. The nitrite concentration was assayed on a microplate by mixing $0.05 \mathrm{~mL}$ of each lung homogenate with $0.05 \mathrm{~mL}$ Griess reagent. Absorbance was measured at $540 \mathrm{~nm}$ and the nitrite concentration was determined by referring to a standard curve of 1-200 $\mu \mathrm{M} \mathrm{NaNO}$. Cytokine concentrations were analyzed in each lung homogenate by sandwich enzyme-linked immunosorbent assay (ELISA). The IFN- $\gamma$ and IL-4 concentrations were measured with commercial antibodies as previously described (10). The absorbance was measured at $450 \mathrm{~nm}$ on a microplate ELISA reader (EMAX; Molecular Devices, USA).

\section{Statistical analysis}

Data are reported as means \pm SE. Statistical analysis was performed by analysis of variance (ANOVA) followed by the parametric Tukey-Kramer test (GraphPad Prism, USA). Significance was defined as $\mathrm{P} \leq 0.05$.

\section{Results}

\section{Increased fungal recovery from the left lungs of $\mathrm{Pb} 18$-infected mice}

We first evaluated the weight differences between the left and right lungs of $\mathrm{Pb} 18$-infected mice at day $70 \mathrm{pi}$. Figure $1 \mathrm{~A}$ shows that the right lungs $(396.8 \pm 59.8 \mathrm{mg})$ were significantly heavier than the left lungs $(185.5 \pm 29.3 \mathrm{mg} ; \mathrm{P} \leq 0.05)$, corresponding to 68.26 and $31.74 \%$ of the total organ mass, respectively (Figure 1B). That the right lungs were anatomically larger than the left ones was expected since, in the mouse, the left lung comprises only a single lobe while the right lung comprises four lobes.
A

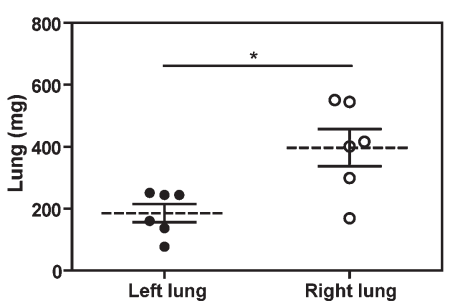

C

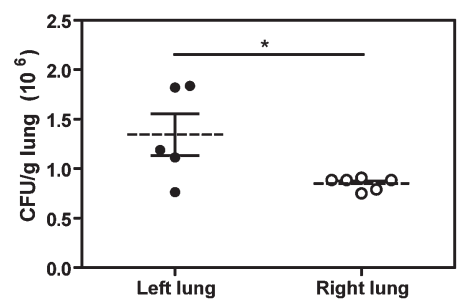

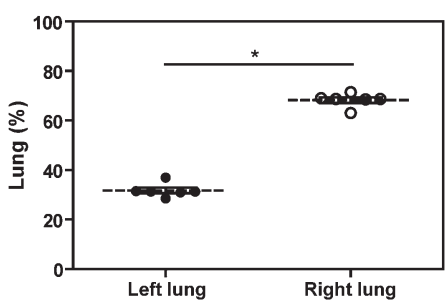

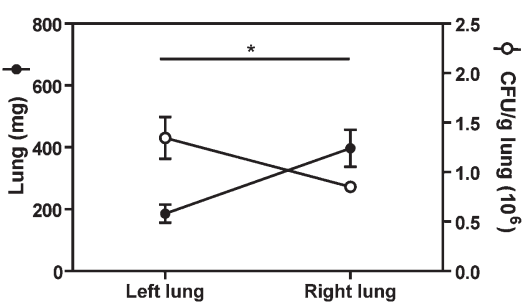

Figure 1. Increased fungal recovery in the left lung of Paracoccidioides brasiliensis-infected mice. Male C57BL/6 mice were challenged intravenously with $1 \times 10^{6}$ viable $P$. brasiliensis 18 (Pb18) yeast cells. $A$, The right and left lungs were weighed individually at day 70 post-infection. $B$, Percent weight of each lung. $C$, Number of colony-forming units (CFU) was determined individually for each lung. $D$, Inverse correlation between the weight of the lungs and the CFU recovered from the pulmonary tissues. Data are reported as means $\pm S E$ of 6 mice. ${ }^{*} P \leq 0.05$ (ANOVA followed by the parametric TukeyKramer test). 
To investigate whether the lungs were differentially affected during the late phase of a systemic experimental model of PCM, we infected C57BL/6 mice with Pb18 yeast cells and evaluated the fungal recovery at day 70 pi. As shown in Figure 1C, the numbers of $\mathrm{Pb} 18$ yeast cells were significantly reduced in the right lungs $(0.85 \pm 0.026 \mathrm{CFU} / \mathrm{g})$ compared with the left lungs $(1.174 \pm 0.24 \mathrm{CFU} / \mathrm{g}, \mathrm{P} \leq 0.05)$. Moreover, an indirect correlation $(\mathrm{P} \leq 0.05)$ was observed between the lung weights and the numbers of CFUs recovered from the pulmonary tissues (Figure 1D). Taken together, these results indicate that the left lungs were preferentially targeted after experimental infection by $\mathrm{Pb} 18$ yeast cells.

\section{Increased NO and IFN- $\gamma$ production in the right lung during experimental PCM}

The NO produced by inflammatory cells has a welldocumented role in fungal clearance (11). We next investigated whether the diminished number of fungal cells observed in the right lungs was associated with increased $\mathrm{NO}$ production. In fact, we observed an increased $\mathrm{NO}$ concentration in the right lung homogenates $\left(0.332 \pm 0.037 \mathrm{mM} \mathrm{NO}_{2}{ }^{-} / \mathrm{g}\right)$, compared to the left lungs $\left(0.221 \pm 0.012 \mathrm{mM} \mathrm{NO}_{2}^{-} / \mathrm{g} ; \mathrm{P} \leq 0.05\right.$; Figure $\left.2 \mathrm{~A}\right)$. Interestingly, the protective response was equally distributed throughout the right lungs, because the four individual lobes had similar concentrations of NO production (data not shown).

Th1 cytokines are involved in NO production and immune protection against fungal infections (12). Our results showed that the right lungs exhibited increased IFN- $\gamma$ production $(4186 \pm 1588 \mathrm{pg} / \mathrm{mL})$ associated with impaired IL-4 synthesis $(567.1 \pm 182.6 \mathrm{pg} / \mathrm{mL})$ in comparison with the left lungs $(691 \pm 200$ and $1286 \pm 439.9 \mathrm{pg} / \mathrm{mL}$, respectively; $\mathrm{P} \leq 0.05$; Figure $2 \mathrm{~B}$ and $\mathrm{C}$ ). Together, these data suggest that Th1 protective responses were induced predominantly in the right lungs during $P$. brasiliensis experimental infections.

\section{Discussion}

In a comparative analysis, we observed that the left lung was more affected than the right lung at day 70 of experimental $P$. brasiliensis yeast cell infection. In addition to increased fungal recovery, we found reduced IFN- $\gamma$ and NO production associated with increased IL-4 synthesis in the left lungs. These results suggest a differential involvement of the right and left lungs during experimental PCM, leading to the triggering of immune responses that were specific to each lung.

Although pulmonary PCM is usually acquired through the respiratory route, we have shown that the lungs of mice inoculated intravenously into the retro-orbital venous plexus are widely affected $(12,13)$. This model reproduces the characteristics of chronic pulmonary disease in humans and offers the advantages of reproducibility and standardization of the number of fungal cells introduced into the host. Additionally, studies that have compared the effectiveness of retro-orbital and tail vein injections in adult mice showed that the two routes can be used interchangeably and are equally effective (14).

Because the needle is placed into the retrobulbar space (the region behind the globe of the eye), the mouse should be anesthetized so that it remains still during the procedure (15). A right-handed operator will likely find it easiest to administer injections into the right retro-orbital sinuses of the mice. An exact description of the mouse retro-orbital sinus seems to be lacking in the literature, but it may be best described as a confluence, pool, or sinus of several vessels that likely includes the supraorbital, inferior palpebral, dorsal nasal, and superficial temporal veins (15). These veins usually end in the superior vena cava, which carries deoxygenated blood from the upper half of the body to the right atrium of the heart. From there, the blood flows through the tricuspid valve into the right ventricle and is then pumped through the pulmonary semilunar valve and pulmonary artery to the lungs. Thus, the fungal cells will not preferentially reach either lung regardless of whether they are inoculated into the right or left retro-orbital sinus.

In humans, the left lung comprises two lobes (superior and inferior) that are separated midway by an interlobular fissure. The right lung, however, comprises three lobes that remain separated by a fissure (superior, middle, and inferior lobes). The presence of a middle lobe makes the right lung larger (increased volume and total capacity) and heavier than the left lung. Similarly, the lungs of mice differ in the number of lobes; however, the right side is
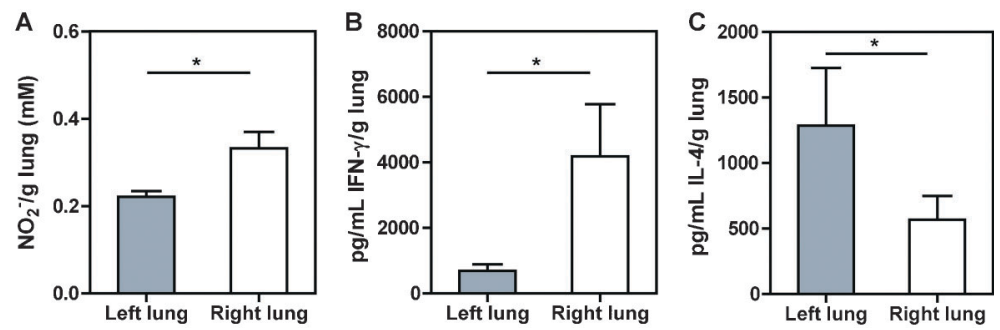

Figure 2. Increased nitric oxide (NO) and interferon- $\gamma($ IFN- $\gamma)$ production in the right lungs of Paracoccidioides brasiliensis-infected mice. Male C57BL/6 mice were infected (intravenously) with $1 \times 10^{6} \mathrm{P}$. brasiliensis $18(\mathrm{~Pb} 18)$ yeast cells. At day 70 post-infection, the concentration of NO was measured with Griess reagent $(A)$. The production of IFN- $\gamma(B)$ and interleukin (IL)-4 (C) in individual lung homogenates was measured by ELISA. Data are reported as means \pm SE of 6 mice. ${ }^{*} \mathrm{P} \leq 0.05$ (ANOVA followed by the parametric Tukey-Kramer test). 
divided into four lobes, while the left comprises only one. In addition to the reduced size, our results showed increased fungal recovery per gram of tissue in the left lung, indicating that the number of yeast cells in the pulmonary milieu did not directly correlate with organ size. Comparable results were found in mice after $P$. brasiliensis conidia infection (16). Further studies of murine lung physiology are necessary to provide a possible anatomicalphysiological explanation.

The differential involvement of bilaterally paired organs during infections has been described. Maned wolves (Chrysocyon brachyurus) contract giant kidney worms (Dioctophyma renale) as pups, and these parasites always infect the right kidney, leading to severe damage or destruction of the organ (17). In children, tuberculosis progression with mucosal ulceration and granuloma formation is more likely to occur in the right lung (18). In West African dwarf goats, lung lesions were more severe in the right compared to the left lung during viral and bacterial pneumonia caused by the peste des petits ruminants virus (PPRV) and Mannheimia haemolytica, respectively (19).

Because the main bronchus is wider, shorter, and more vertical on the right side than the left side, we expected that the right lung would be more affected during experimental PCM. Because the exact mechanism that favors fungal growth in the left lung is unknown, we suppose that the rapid heart rate in the mouse, which varies from 488 to 594 bpm (20), might induce vigorous vibrations in the left

\section{References}

1. Teixeira MM, Theodoro RC, de Carvalho MJ, Fernandes L, Paes HC, Hahn RC, et al. Phylogenetic analysis reveals a high level of speciation in the Paracoccidioides genus. $\mathrm{Mol}$ Phylogenet Evol 2009; 52: 273-283, doi: 10.1016/j.ympev. 2009.04.005.

2. Coutinho ZF, Silva D, Lazera M, Petri V, Oliveira RM, Sabroza PC, et al. Paracoccidioidomycosis mortality in Brazil (1980-1995). Cad Saúde Pública 2002; 18: 14411454, doi: 10.1590/S0102-311X2002000500037.

3. Telles FQ. Paracoccidioidomicose: uma importante descoberta. Prática Hosp 2008; 10: 23-25.

4. Benard G. An overview of the immunopathology of human paracoccidioidomycosis. Mycopathologia 2008; 165: 209221, doi: 10.1007/s11046-007-9065-0.

5. Montenegro MRG, Franco M. Pathology. In: Franco MF, Lacaz CS, Restrepo A, Delnegro G (Editors), Paracoccidioidomycosis. Florida: CRC Press; 1994. p 131-150, and 175-184

6. Robledo MA, Graybill JR, Ahrens J, Restrepo A, Drutz DJ, Robledo M. Host defense against experimental paracoccidioidomycosis. Am Rev Respir Dis 1982; 125: 563-567.

7. San-Blas G. Paracoccidioides brasiliensis: cell wall glucans, pathogenicity, and dimorphism. Curr Top Med Mycol 1985; 1: 235-257, doi: 10.1007/978-1-4613-9547-8_9.

8. Calich VL, Purchio A, Paula CR. A new fluorescent viability test for fungi cells. Mycopathologia 1979; 66: 175-177, doi: 10.1007/BF00683967.

9. Singer-Vermes LM, Ciavaglia MC, Kashino SS, Burger E, pulmonary artery that could preferentially facilitate the delivery of yeast cells to the left lung. Future studies directed toward the investigation of the role of heart vibration in distribution of the infective inoculum during PCM could be very interesting and enlightening. Future research should determine the fungal distribution in the lungs at different pi times, and differences associated with the number of fungal cells administered, the use of mice with different genetic backgrounds, and infection by diverse $P$. brasiliensis strains.

In conclusion, this study demonstrated the differential involvement of the right and left lungs at day 70 after the experimental infection with $P$. brasiliensis yeast cells. This knowledge emphasizes the need of an accurate and standardized protocol for tissue collection during studies of experimental PCM, since experiments using the same lungs favor the collection of comparable data from different mice.

\section{Acknowledgments}

The authors thank Dr. Isabel Kinney Ferreira de Miranda Santos and Dr. Luciano Aparecido Panagio for their comments on early drafts and discussion of the manuscript. We gratefully acknowledge the technical support of Wander C.R. da Silva and Lúcia Pacheco, and the excellent secretarial support of Ana Cristine $S$. Ferreira. Research supported by FAPESP (\#2006/ 56155-9) and CNPq.
Calich VL. The source of the growth-promoting factor(s) affects the plating efficiency of Paracoccidioides brasiliensis. J Med Vet Mycol 1992; 30: 261-264, doi: 10.1080/ 02681219280000331

10. Livonesi MC, Rossi MA, de Souto JT, Campanelli AP, de Sousa RL, Maffei CM, et al. Inducible nitric oxide synthasedeficient mice show exacerbated inflammatory process and high production of both Th1 and Th2 cytokines during paracoccidioidomycosis. Microbes Infect 2009; 11: 123-132, doi: 10.1016/j.micinf.2008.10.015.

11. Nascimento FR, Calich VL, Rodriguez D, Russo M. Dual role for nitric oxide in paracoccidioidomycosis: essential for resistance, but overproduction associated with susceptibility. J Immunol 2002; 168: 4593-4600.

12. Livonesi MC, Souto JT, Campanelli AP, Maffei CM, Martinez $R$, Rossi MA, et al. Deficiency of IL-12p40 subunit determines severe paracoccidioidomycosis in mice. Med Mycol 2008; 46 637-646, doi: 10.1080/13693780801982762.

13. Tristão FS, Rocha FA, Moreira AP, Cunha FQ, Rossi MA, Silva JS. 5-Lipoxygenase activity increases susceptibility to experimental Paracoccidioides brasiliensis infection. Infect Immun 2013; 81: 1256-1266, doi: 10.1128/IAI.01209-12.

14. Steel CD, Stephens AL, Hahto SM, Singletary SJ, Ciavarra $\mathrm{RP}$. Comparison of the lateral tail vein and the retro-orbital venous sinus as routes of intravenous drug delivery in a transgenic mouse model. Lab Anim 2008; 37: 26-32, doi: 10.1038/laban0108-26. 
15. Yardeni T, Eckhaus M, Morris HD, Huizing M, HoogstratenMiller S. Retro-orbital injections in mice. Lab Anim 2011; 40: 155-160, doi: 10.1038/laban0511-155.

16. Lopera D, Naranjo T, Hidalgo JM, de Oliveira Pascarelli BM, Patino JH, Lenzi HL, et al. Pulmonary abnormalities in mice with paracoccidioidomycosis: a sequential study comparing high resolution computed tomography and pathologic findings. PLoS Negl Trop Dis 2010; 4: e726, doi: 10.1371/ journal.pntd.0000726.

17. Matera EA, Saliba AM, Matera A. The occurrence of dioctophymiasis in the Maned Wolf (C. brachyurus). Int Zoo Yb 1968; 8: 24-27, doi: 10.1111/j.1748-1090. 1968.tb00427.x

18. Buxi TB, Sud S, Vohra R. CT and MRI in the diagnosis of tuberculosis. Indian J Pediatr 2002; 69: 965-972, doi: 10. 1007/BF02726016.

19. Emikpe BO, Akpavie SO. The pattern of distribution of pneumonic consolidation in experimental peste des petits ruminants virus (PPRV) and/or Mannheimia haemolytica infection in West African Dwarf Goats. Int J Morphol 2010; 28: 563-568, doi: 10.4067/S0717-95022010000200037.

20. Spani D, Arras M, Konig B, Rulicke T. Higher heart rate of laboratory mice housed individually vs in pairs. Lab Anim 2003; 37: 54-62, doi: 10.1258/002367703762226692. 